secretion, supposed to have been ascertained by microscopic examination." Now, Sir, it unfortunately often happens, that in order to serve a certain purpose, a portion only of some particular sentence, or remarks, is quoted, and inferences are arrived at by the reader that would be totally different from those which would be deducible were the quotation not so. limited. Mr. Syme's remarks would lead persons to infer that he attributed death in my patient merely to some disease of the kidney which I had conjured up by a microscopic examination, and that $I$ had entirely left out the diseased condition of the vertebra or cotyloid cavity, as contributing to his death; but if the reader will be so kind as to look to my report he will find the following remarks-whilst speaking of the fatal termination: "The post-mortem examination revealed so much mischief, as to show that this benefit conld only be but temporary, and that it was impossible for Nature to bear up with eventual success, although one great source of irritation had been removed. The disease in the lumbar vertebra was sufficient alone, $I$ apprehend, to prevent the patient from completely rallying; but there is little doubt that the real cause of death was the disordered condition of the kidneys." Thus it will be acknowledged by every fair reader that I had by no means omitted to mention the disease of the vertebræ, as preventing the success of this operation; although $I$ have stated, and still fully believe, from the symptoms the patient laboured under, that a fatty degeneration of the kidney was the exciting cause of his death. I did not wish to induce persons into the belief that the patient would have recovered had not the kidneys been so diseased -at the same time I have no hesitation in affirming, that he would have lived much longer, even though there were superficial caries of the vertebræ, and disease of the acetabulum, provided the renal organs had been quite sound. But Mr. Syme, it appears, insinuates that there was no disease of the kidney, when he talks of "this disordered condition being referred from something in the secretion, supposed to have been ascertained by microscopic examination." I only have again to state, as I stated in the original report, that not only was serious disease of the kidney diagnosed by that excellent and faithful observer, Dr. George Joluson, some time before the death of the patient, but that, by careful examination after death by the same gentleman this diagnosis was perfectly verified; so that it was not merely a supposition of disease from "something.in the secretion, supposed to have been ascertained by mieroscopic examination," but there was ample evidence of the disease from ocular examination of the organ itself after-death; and such men as Messrs. Fergusson, Alexander Ure, and George Johnson are not likely to be mistaken in the morbid appearances of parts.

Now that I have done with the portion of the subject which was somewhat personal, I cannot. help making reference to some of the remarks by Mr. Syme respecting the impropriety of this operation; and I can assure that gentleman, that it is with all due respect for him as a great surgeon and distinguished authority, that $I$ do so. I cannot help feeling that it would be, in any ordinary matter, presumptnous and ridiculous in me to attempt to oppose any opinion of $\mathrm{Mr}$. Syme; but my excuse for doing so now will be, I hope, the great attention I have paid to the subject, and the increasing interest $I$ feel in it. Mr. Syme protests strongly against this operation, and states that "excision of the head of the thighbone for caries of the joint, should be regarded as no less erroneous in theory than objectionable in practice." And why? Because he states that the acetabulum is always diseased, and that it will not admit of removal. This is the grand argument with the opponents of this operation; but those who use it are either forgetful or ignorant of the changes which takes place in disease of the hip-joint of long standing. Admitting that caries vsually involves the acetabulum to some extent, I nevertheless can affirm, from my own experience and knowledge, that there are certain instances in which serious disease is confined to the head of the femur, whilst none exists in the pelvic side of the joint. In all the successful cases in this country there was no disease of the acetabulum at the time the operations were performed, although there probably had been caries at a previous period of the complaint. In all of them the acetabulum was found to be so contracted as to leave hardly a vestige of the natural cavity, or it-was filled up with new bone, which had been thrown out in the process of reparation; and yet, with all this, the head of the thigh-bone lay in its abnormal position, in a more or less carious condition, causing all the severe disturbance which was noticed in each case. Such, I apprehend, will be the condition of the parts in those cases in which this operation should be performed; and it is by no means difficult to under- stand how it happens that the disease in the acetabulum stops whilst that in the thigh-bone persists. Every surgeon is aware how, in caries of joints, new bone becomes deposited around them; and more especially how the sockets of jointo become altered in their shape and appearance. In the instance of disease of the hip, after dislocation, and consequently after the removal from the socket of a foreign body, (which in fact the carious head of the femur must be,) a reparative process goes on, and new bone fills up the original cavity whilst the head of the femur, from its large globular form, and from its peculiar texture, rarely takes on this process, but re mains in its abnormal situation, acting essentially as a foreign body; therefore I cannot agree with Mr. Syme in consider ing the operation "erroneous in theory;" and as regards the practical value of the operation, this has been ascertained fully by $\mathrm{Mr}$. White, whose death we have just now to deplore, and Mr. Fergusson; and those who will attentively read the history and symptoms of those cases published by these gentlemen, will be convinced of this; or if any gentleman will take the trouble to pay a visit to King's College Hospital at the present time, he will see striking evidence of the benefit of this operation in the case of the little girl on whom Mr. Fergusson operated about two months since. She is now able to move about the ward, and with the aid of crutehes is able to put her foot to the ground.

But, Sir, in his attack upon this operation, Mr. Syme has entirely overlooked the main objection to it. He has not. hinted at the great liability there is in such cases to the im. plication of some important organ in the scrofulous disorder, which is, for the most part, the cause of hip-disease. It is here that the main difficulty lies; and here, I am afraid that superficial observers and too ardent operators will fall into error. This operation, I am persuaded, might be accomplished in many instances with success, were it not for the fact of co-existent disease. I have at this present moment under my care a little patient in whom the condition of the hip is such, that I should not hesitate to resort to the operation; but the liver is enlarged, I suppose by some scrofulous or fatty deposit. In such an instance, it would, of course, be worse than useless to cut out the head of the femur. Further experience of this proceeding will soon settle the question as regards its propriety; and although the opinion of so eminent an authority as Mr. Syme will, to a great degree, retard its general adoption, at the same time, the opposition of one authority alone, however distinguished, will not, I am sure, in a liberal profession like ours, have the effect of causing the hasty abandonment of a proceeding which has been proved in several instances to be so eminently serviceable to those unfortunate beings who suffer from intractable and incurable disease of the hip-joint.

At the conclusion of his remarks, allusion is made to my inexperience and youth; and there, $I$ admit, $M r$. Syme has me; but this I cannot help, and there can be no doubt that it is a fault decreasing every day. At the same time, I must beg to state, what I hope those who know me at least will give me credit for, that it has not been without deep and serious reflection upon all points connected with this important subject, and not without having examined and paid great attention to nearly every case in which the operation has been performed in this country, that $I$ have urged its propriety upon the profession. I cannot expect that any remarks of mine will be considered to have great weight; but I hope that the sentiments of one who is best qualified, both by his position and experience, to judge of the propriety of this proceeding, will soon be fully made known; and I have no doubt that then the enlightened practitioners of surgery in Great Britain will determine whether this operation should be resorted to or not.-I am, Sir, yours obediently, Caroline-street, Bedford-square, March, 1848. HenrT SMith.

\section{MR. GAY AND HIS REVIEWERS.}

[LE'TTER FROM MR. GAY.]

To the Editor of The LANCET.

Srr,--I hope, by a few words, to close a correspondence with Mr. Luke, which I sincerely trust may not "leave any recollection of offence on either side."

I cannot, however, admit that in my first letter, by the use of even an ambiguous expression, I led your readers to infer that, after Mr. Luke's disavowal, $I$ persisted in attributing to him, or to either of his colleagues at the London Hospital, "the opinion alluded to by the editor" of the Medico-Chirurgical Review. My allusion in that letter to the circumstances which had transpired between Mr. Luke and myself 
was made for the twofold purpose of showing, first, that to my regret $I$ had been (I believe) wilfully misled by a statement which the editor of that journal (Dr. Carpenter, I presume) had thought proper to make privately to myself, for the purpose of justifying the publication of an insolent and malicious attack upon my character; and, secondly, that I had obtained sufficient evidence for my assertion, that the editor's statement was, "on the face of it, a falsehood."

I really thought the following passage from my letter sufficiently explicit to prevent any such misapprehension of my meaning as Mr. Luke and his friends entertained:-

"But, Sir, I aver, and will prove, that the article was written by a person comparatively as ignorant of the subject as the editor appears to be of the first principles of honour and justice; and, therefore, that the statement of its having been declared to be 'perfectly just' by 'a London Hospital Surgeon,' or, if the Editor prefers it, by ' $a$ Surgeon to a London Hospital, distinguished for his acquaintance with the subject,' is, on the face of it, a falsehood."

Mr. Luke continues to complain that I did not publish his letter with those of Mr. Key and Mr. Lawrence; but I really did not see the slightest necessity for it, nor do I feel that in withholding it I am open to the imputation of having practised reserve. Mr. Luke's letter was intended simply to correct an unfounded impression; and the occasion which called it forth having, in my opinion, passed a way with the mutual explanation that followed, I did not for a moment deem it requisite that $I$ should do more than convey to the minds of your readers, in as concise a manner as possible, what I conceived to be its chief purport. I have no wish that the letter should not see the light; and, as far as I am concerned, Mr. Luke is quite at liberty to do whatever he may think proper with it. The letters of Mr. Lawrence and Mr. Key, on the other hand, were of very different import, and were made public by me, after giving some examples of the grossest ignorance that was ever displayed in a journal of equal pretensions, in order to counteract the impression which its "Sir Oracle" intended to produce on the minds of the profession at large.

I beg again, in conclusion, to state that I have never for a moment seriously entertained the thought that either Mr. Luke or his colleagues had any connexion with the opinion relative to the review in question, which has been, so unworthily, "an apple of discord"" and if any statement which I have made has led your readers to believe that Mr. Luke had been, or could be, "guilty of unfairness" to myself or any one else, I trust $I$ have said enough to show that $I$ never meant that such an interpretation should be placed upon it.

I have the honour to be, Sir, your obedient servant Finsbury-place South, March, 1849. JOHN GAY.

\section{ftilevícal $\mathbf{3}$ (2ews.}

Apothecaries' HatL.-Names of gentlemen who passed their examination in the science and practice of medicine, and received certificates to practise, on Thursday,

March 8th, 1849.

Dafidson, Frederick Montgomerie Davenport, Dawlish, Devon.

Johnson, William Henry, Weymouth, Dorset.

Lemer, Henry Payne, Bury St. Edmunds.

Oughton, Frederick, Camberwell.

Welsh, Francis Fawcett, Saffron-Walden, Essex.

Wilts Lunatic Asxudm.-The committee of visitors have, out of a list of upwards of thirty candidates, appointed Dr. Thurnam, of the Retreat, near York, to the important and responsible situation of medical superintendent-an appointment which has, we understand, given the greatest satisfaction. The plan of the proposed building, furnished by T. $\mathrm{H}$. Wyatt, Esq., has met with the approval of the secretary of state; all that now remains is to advertise for tenders, and to commence the building without delay.-Salisbury and Winchester Journal.

The Cholera In France.-At Raches, a village situated near Douai, the cholera is making sad havoc. Up to the 15th of February there had been 27 cases and 9 deaths in this little place. Letters from St. Lo, of the 19th of February, state that the disease has been reigning for the last six weeks at Dieppe; from the city it is now spreading into the suburbs. A mother who was nursing a child stricken with cholera, died of the disease soon afterwards. M. Houvernilt, mayor of the village of Wissant, near Calais, has just died of cholera; and the mayor of Guines (M. Dumbron) has also fallen a victim to the disease. In this latter place and neighbourhood the epidemic has carried off more than one hundred persons; there were as many as six and eight burials in one day, which for so small a town is enormous. The disease has, however, disappeared almost completely.

TrPHOS IN ITALY.-Typhus is making extensive ravages in the province of Aosta (Piedmont). The Sardinian government has just sent Dr. Zanetti thither, with the view of obtaining an accurate report of the actual state of the province.

Appolntment.-Professor Cantée has just been maintained for five more years in the office of dean of the medical faculty of Turin.

EXPULSION.-Dr. London, one of the official examiners of the medical faculty of Berlin, has just been expelled from the Prussian capital, on account of the active share he took in late disturbances there.

Medtco-Ethical Societr, Manchester.-The first annual dinner of this Society was held on Saturday evening, February 24th,-Dr. J. L. Bardsley in the chair. The Chairmen, after dinner, remarked that Mr. Allen, the founder of the associa. tion, had met with most able coadjutors. The present strength of the Societywas sixty-nine members, comprising the names of some who had not only adorned their calling by their conduct in the particular localities in which they resided, but whose researches and writings had advanced the practice and the cause of the medical profession. He alluded to an objection which he had heard that the association partook of the character of a medical inquisition. Now, in only one instance, had the committee been appealed to in its judicial character; and some of their friends, so far from considering the Society inquisitorial, had availed themselves of its instrumentality for the adjustment of professional misunderstandings, and the maintenance of professional etiquette. It was one of the great objects of the Society not to encourage, but to prevent, disagreements amongst medical men. The end and aim of the institution was the maintenance and advancement of the respectability of the profession. Mr. Allen stated that the secretaries had been in correspondence with gentlemen at Liverpool, Warrington, and Stockport, respecting the formation of medico-ethical associations in those towns. Two cases of private grievances had been adjusted by the Society within the last fortnight, and two other cases had been sent in for consideration, provided an agreement was not made in the meantime. He referred to the admirable working of the code of etiquette. Rules were said to be altogether unnecessary among gentlemen. He submitted that rules could regulate gentlemen, and hence the advantage of uniformity of action. The advantage, utility, and practicability of rules were ad. mitted by other professions, and why not with them? The committee of the assnciation in tended to direct their attention to cases of illegal practice in this town, by which so much injury was done to the profession as well as to the public. The law was most defective with regard to such cases. It was very evident, therefore, they could only be reached through the legislature; and here was to his own mind suggested a most important argument in favour of the necessity of combination in the medical profession. Dr. Bardsley, sen., Mr. Wilson, and many other gentlemen addressed the meeting, which appeared to have conferred general satisfaction. (We regret that we have not space for a longer report.)

MEDICAI SocIETY OF LoNDON. - The seventy-sixth anniversary meeting of the Society was held on Thursday, March 8th, at the Albion Tavern, - the President, Mr. Hancock, in the chair. The Oration was given by Dr. Hughes Willshire, and was entitled the "Moral Aspects of Medical Life." The Fothergillian gold medal was given to John Milligan, Esq., of Keighley, Yorkshire, and the silver medal to $\mathrm{D}_{\mathrm{r}}$. Willshire. The following gentlemen were elected office-bearers for the ensuing session :-President: H. Hancock, Esq.,-Vice-Presidents : Dr. Chowne, Mr. Dendy, Dr. Waller, and Mr. Hird,Treasurer: Mr. Clifton,-Librarian: Mr. Harrison,-Secre taries in Ordinary: Dr. Smiles and Dr. Bowie,-Secretary for Foreign Correspondence: Dr. Davidson,-Councillors : Messrs. Eales, Headland, Hutchinson, Linnecar, Middleton, Pilcher, Holding, Robarts, Stedman, Drs. Clutterbuck, Rowland, Lever, Crisp, Mr. Harvey, Dr. Willshire, Mr. Barlow, Mr. Todd, Mr. Lowe, Dr. G. Bird, and Dr. Cogswell,-Fellow to deliver the Oration in 1850 : Mr. Hilton. The Fellows of the Society and their friends, to the number of nearly sixty, sat down afterwards to an excellent dinner. The conviviality was kept up to a late hour.

Funeral of Mr. Pennington.-The remains of this respected member of our profession were interred on Wednesday last, at the Foundling Hospital. The procession was joined by a great number of medical men. 